\title{
Experience with Thin Superpave Mixture Overlay of Small Aggregate Top Size in Kansas
}

\author{
Farhana Rahman, Mustaque Hossain, Stefan A. Romanoschi, \\ and Cliff Hobson
}

\begin{abstract}
Superpave $^{\circledR}$ asphalt mixture with small (4.75-mm) nominal maximum aggregate size (NMAS) is a promising, low-cost pavement preservation treatment for rural roads. This mixture has the potential to provide a smooth riding surface, be applied in thin lifts, correct surface defects, decrease construction time, and provide an economical surface mixture for low- to medium-volume facilities. Because of budget constraints in highway construction and preservation programs and the economic advantages of such a mixture, many highway agencies are considering implementing it for rural roads. Two rural highway pavements in Kansas were overlaid with a 15- to 19-mm-thick 4.75-mm NMAS Superpave mixture in 2007. Overall, the experience in Kansas with the 4.75-mm NMAS mixture was varied. Both projects had construction issues. Experience on one project showed that extended aggregate drying and drum cleaning would be necessary when producing these mixtures. Performance history on both projects after overlay construction showed that roughness of the road surface was significantly improved and was consistent for the 3 years after the overlay. Transverse cracks seem to be the major concern, although the rutting performance of this small-sized aggregate mixture is satisfactory. Crushed gravel aggregates seemed to perform better in the mixture than crushed limestone aggregates. A binder with a higher grade may be needed to address transverse cracking issues.
\end{abstract}

The Superpave ${ }^{\circledR}$ mix design procedure has been adopted by many state agencies during the past decade. It consists of mix design criteria for 9.5- to 37.5-mm nominal maximum aggregate size (NMAS) mixes. Until 2001, 9.5-mm was the smallest NMAS used in the Superpave mix design. In 2002, the National Center for Asphalt Technology (NCAT) developed Superpave mix design criteria for the 4.75-mm NMAS mix (1). Before Superpave implementation, many state agencies successfully used fine mixes for various maintenance applications on low-traffic-volume roads (2). Recently many state agencies have expressed their interest in implementing 4.75-mm NMAS Superpave-designed mixtures for thin-lift applications, leveling courses, and roadway maintenance (3), an interest confirmed by a

F. Rahman and M. Hossain, Department of Civil Engineering, Kansas State University, Manhattan, KS 66506. S. A. Romanoschi, Department of Civil and Environmental Engineering, University of Texas at Arlington, UTA Box 19308, Arlington, TX 76019-0308. C. Hobson, Materials and Research Center, Kansas Department of Transportation, 2300 Van Buren, Topeka, KS 66611. Corresponding author: F. Rahman, frahman789@gmail.com.

Transportation Research Record: Journal of the Transportation Research Board, No. 2205, Transportation Research Board of the National Academies, Washington, D.C., 2011, pp. 3-10.

DOI: 10.3141/2205-01 nationwide survey of state highway agencies conducted by NCAT (4). Most states agencies used crushed rock or chips, screenings, and natural sand in the 4.75-mm NMAS mixture. The common grade of asphalt used in the mix was PG 64-22. Hydrated lime was commonly used as an antistripping agent. Both Superpave and Marshall methods were used for designing the 4.75-mm NMAS mixes. For the Superpave method, the compactive effort $\left(N_{\text {des }}\right)$ of 50 gyrations was typical. Of states using the Marshall mix design method, only Missouri, which is a major user of this mixture, disclosed its design criteria ( 35 blows). Most states did not have in-place density requirements. Tables 1 and 2 summarize some other results of this survey.

\section{PROBLEM STATEMENT AND OBJECTIVE}

A recent survey on Superpave-designed pavements proves that permeability is one of the biggest problems in pavement design. The survey suggested that coarse-graded Superpave mixes result in higher permeability compared to the dense-graded mixes at the same air void (5). Mixes with 4.75-mm NMAS can potentially improve ride quality and surface friction characteristics, extend pavement life, increase durability, and reduce permeability of low-volume road pavements (2). Many states, including Kansas, are looking at less costly pavement preservation techniques for rural roads because of budget constraints. Since a few states have had positive experiences with thin hot-mix asphalt overlays, the 4.75-mm mixes have drawn renewed attention from many state agencies. Since the mixes are placed in thin-lift applications, they can be used for corrective maintenance, decrease construction time and cost, and provide an economical surface mix for low-traffic-volume facilities. Potential limitations for small aggregate-size mixtures include concerns with permanent deformation, moisture resistance, scuffing, and skid resistance. In addition, before 2002, the gradation criteria followed by state agencies varied and were put in place on the basis of the different experiences of project personnel. In 2002, the 4.75-mm NMAS designation and criteria were added to the AASHTO Superpave specifications to fit the need for small aggregate-size mixtures. These criteria were based on a combination of experience, limited laboratory research, and engineering judgment. Thus, no study has been reported on the large-scale use of this mix in the field.

The main objective of this paper is to discuss the construction and performance of 4.75-mm NMAS overlays on two rural roads in Kansas. The study investigates the effectiveness of this ultrathin bonded overlay with respect to roughness and some other major distresses common on Kansas highways. 
TABLE 1 Responses to Survey Regarding 4.75-mm NMAS Mixture Production (4)

\begin{tabular}{ll}
\hline State & Approximate Production Quantity \\
\hline Delaware & $<1,000$ tons \\
Georgia & 320,000 tons in fiscal year 2004 \\
Tennessee & 225,000 tons \\
West Virginia & $15,000-20,000$ tons \\
Arizona & $250,000-350,000$ tons \\
South Carolina & Approximately $5 \%$ of total tonnage \\
South Dakota & 75,000 tons \\
Missouri & 1.7 million tons for surface level, and 750,000 tons \\
North Carolina & 75,000 tons \\
\hline
\end{tabular}

\subsection{5-mm SUPERPAVE MIXTURES IN KANSAS}

Currently, 4.75-mm NMAS Superpave mixture is designated as SM-4.75A in Kansas. Gradation of the mixture is selected to pass over the maximum density line (MDL) on a 0.45 power chart in sand size and thus, the mixture is fine. Combined gradations for the projects are shown in Figure 1. The figure also shows the upper control points (UCP) and lower control points (LCP) of aggregate gradation with 4.75-mm NMAS. The gradation chart indicates gradation of the SM-4.75A mixture is essentially controlled by the materials retained on 1.18-mm (0.05-in.) and 0.075-mm (0.003-in.) sieves. The current Kansas Department of Transportation (DOT) specifications also allow use of up to $35 \%$ natural sand, provided the fine aggregate angularity of the blend meets the required criteria (min. 42). Table 3 shows required mixture design criteria, and Table 4 shows required aggregate criteria. These are similar to aggregate criteria for other Superpave mixtures with similar design traffic and position within the pavement.

\section{DESCRIPTION OF KANSAS SM-4.75A PROJECTS}

Two rehabilitation projects on US-160 and K-25 were constructed in 2007 by using 4.75-mm NMAS Superpave mixture overlay.
TABLE 2 Responses to Survey Regarding 4.75-mm NMAS Mixture Usage (4)

\begin{tabular}{ll}
\hline State & Usage and Further Development \\
\hline Florida & Leveling and thin overlay \\
New Jersey & Leveling on concrete pavement overlay \\
Vermont & Low ESAL Superpave \\
Hawaii & Thin overlay for preventive maintenance \\
Nevada & Fill substantial cracking (attempt failed \& discontinued) \\
North Dakota & Bike trails \\
Washington & Thin-wearing surface over structurally sound pavement \\
Delaware & Subdivision overlay work \\
Georgia & Low-volume local roads and parking lots \\
Illinois & Explore ways to add macro texture as a surface course \\
South Dakota & All types of roads (surface mix) \\
Missouri & Long-lasting surface mixtures for low-volume roadways \\
Iowa & Application as scratch-course mix
\end{tabular}

\section{US-160, Harper County}

This project was constructed on a two-lane, two-way highway in rural south-central Kansas. Project length was about $29 \mathrm{~km}$ (18 mi). Project scope consisted of a 50-mm (2-in.) hot-in-place recycling (HIPR) followed by a $19-\mathrm{mm}(0.75$-in.) SM-4.75A mixture overlay. Figure $2 a$ shows the cross section of this project. Annual average daily traffic varied from 625 to 1,398 in 2006 . Average daily equivalent $80-\mathrm{kN}$ (18-kips) axle loads varied from 91 to 177 . The 20-year design equivalent single-axle load (ESAL) for the overlay was 1.7 million.

\section{K-25, Rawlins County}

The second project was on a two-lane, two-way rural highway in northwest Kansas. Project length was about 26 km (16 mi). Project scope consisted of 25-mm (1-in.) HIPR followed by a 16-mm (0.625-in.) SM-4.75A mixture overlay. Figure $2 b$ shows the cross section of this

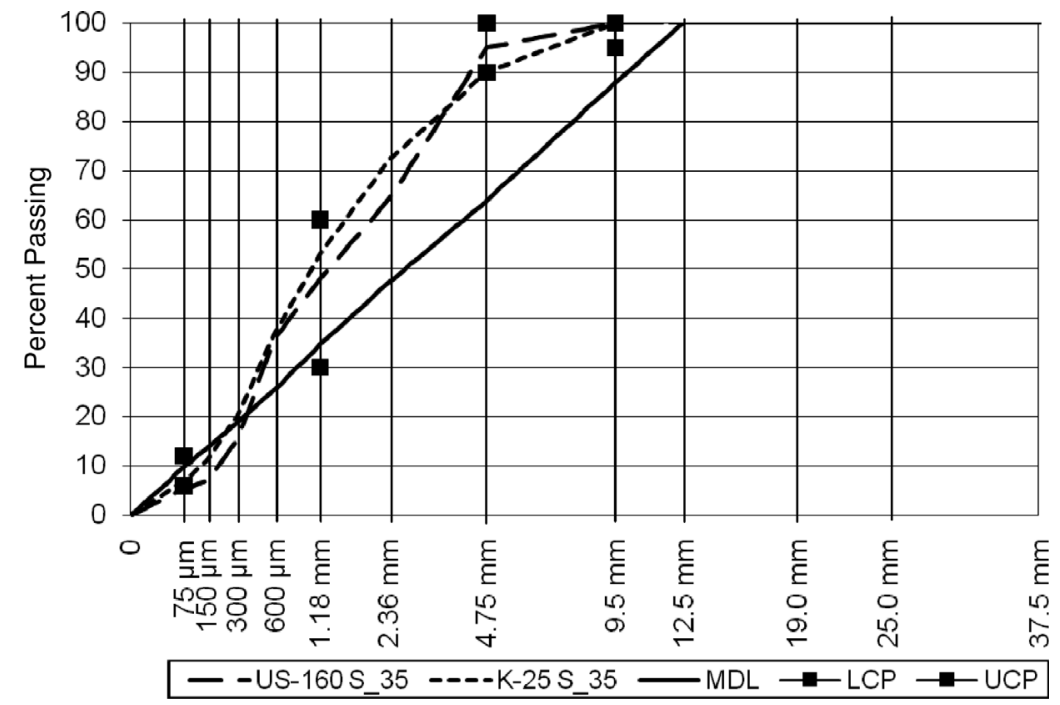

FIGURE 1 Power chart $(0.45)$ for combined gradation. 
TABLE 3 Mixture Design Criteria for Kansas 4.75-mm NMAS Superpave Mixtures (6)

\begin{tabular}{lll}
\hline Criterion & Specifications & Comments \\
\hline $\begin{array}{l}\text { Compaction effort: } N_{\text {ini }}, N_{\text {des }} \text {, and } N_{\max } \\
\text { Volumetric properties }\end{array}$ & Function of 20-year design ESALs & Similar to all other Superpave mixes \\
$\quad$ Air voids & $4 \% \pm 2 \%$ at $N_{\text {des }}$ & \\
VMA & $\begin{array}{c}16 \% \text { min. for reconstruction or } \\
\text { major modification project }\end{array}$ & $\begin{array}{l}\text { Similar to all other Superpave mixes } \\
\text { May be reduced by 1\% for 1R jobs }\end{array}$ \\
VFA & $65-78$ & Function of 20-year design ESALs \\
$\% G_{\mathrm{mm}} @ N_{\text {ini }}$ & 90.5 & Function of 20-year design ESALs and \\
$\% G_{\mathrm{mm}} @ N_{\max }$ & 98.0 & layer depth \\
$\quad$ Dust-to-binder ratio & $0.9-2.0$ & Similar to all other Superpave mixes \\
Tensile strength ratio, min. $(\%)$ & 80 & $0.6-1.2$ or 0.6-1.8 \\
\hline
\end{tabular}

NOTE: $N_{\mathrm{ini}}=$ initial number of gyrations, $N_{\max }=$ maximum number of gyrations, $1 \mathrm{R}=$ resurfacing, and $G_{\mathrm{mm}}=$ theoretical maximum specific gravity of the mix.

TABLE 4 Aggregate Requirements for Kansas SM-4.75A Mixture

\begin{tabular}{lcccc}
\hline & & \multicolumn{2}{c}{ Project Data } \\
\cline { 3 - 5 } Aggregate Property & Criteria & US-160 & K-25 \\
\hline Coarse aggregate angularity (min. \%) & 75 & 99 & 80 \\
Uncompacted voids-fines (min. \%) & 42 & 43 & 44 \\
Sand equivalent (min. \%) & 40 & 40 & 78 \\
Antistripping agent & - & Yes & No \\
\hline
\end{tabular}

NOTE: $-=$ not applicable.

${ }^{a} 20$-year design ESALs $=1.7$ million.

${ }^{b} 20$-year design ESALs $=1.5$ million.

project. Annual average daily traffic varied from 423 to 488 in 2006. Average daily equivalent $80-\mathrm{kN}$ (18-kips) axle loads varied from 68 to 92 . The 20-year design ESAL for the overlay was 1.5 million.

\section{CONSTRUCTION MATERIALS}

\section{SM-4.75A Overlay Mixture Composition}

Table 5 shows the mixture composition for the 4.75-mm Superpave mixture used on both projects. The mixture on US-160 had $32 \%$ crushed limestone, $33 \%$ crushed limestone screening, and 35\% natural sand. The K-25 mixture had 30\% crushed gravels, 33\% crushed gravel screening, $35 \%$ natural sand, and $2 \%$ microsilica. The design asphalt content was $7.0 \%$ for US-160 and $6.1 \%$ for K-25 by weight of total mixture. The binder grade was PG 64-22 on both projects. An antistripping agent was used in the mixture for the US-160 project. Microsilica was not used in production since the required voids in mineral aggregate (VMA) was obtained without it in production.

\section{Hot-in-Place Recycling}

The US-160 project had $50 \mathrm{~mm}$ (2 in.) of HIPR. A mix design was done. The target asphalt rejuvenating agent (ARA-1P) rate, based on dry weight of reclaimed asphalt pavement, was $2.0 \pm 0.2 \%$. Thus, the recommended spread rate was $2.22 \pm 0.05 \% \mathrm{~L} / \mathrm{m}^{2}(0.49$ $\left.\pm 0.05 \% \mathrm{gal} / \mathrm{yd}^{2}\right)$. The adjusted field application rate was $1.36 \mathrm{~L} / \mathrm{m}^{2}$ $\left(0.3 \mathrm{gal} / \mathrm{yd}^{2}\right)$. The K-25 project had $25 \mathrm{~mm}$ (1 in.) of HIPR depth. No mix design was done to find the emulsion rate as per Kansas DOT practice. In the field, the emulsion rate was adjusted until the contractor and Kansas DOT agreed on the adequate rate for proper rejuvenation and minimal bleeding. The planned emulsion rate was $0.68 \mathrm{~L} / \mathrm{m}^{2}\left(0.15 \mathrm{gal} / \mathrm{yd}^{2}\right)$, but only $0.52 \mathrm{~L} / \mathrm{m}^{2}\left(0.114 \mathrm{gal} / \mathrm{yd}^{2}\right)$ was actually used.

\section{Tack Coat}

The tack coat used on both projects was SS-1HP with about $60 \%$ asphalt residue. The target application rate was $0.18 \mathrm{~L} / \mathrm{m}^{2}$ $\left(0.04 \mathrm{gal} / \mathrm{yd}^{2}\right)$. In the field, this rate was adjusted until the contractor

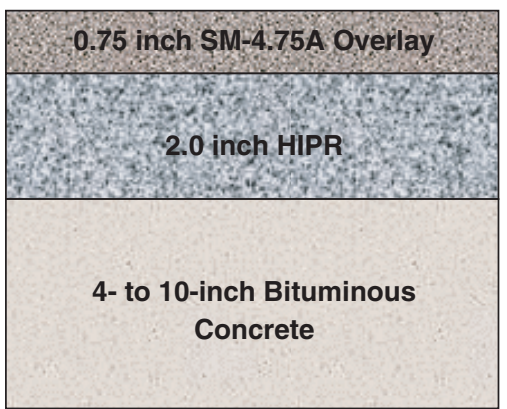

(a)

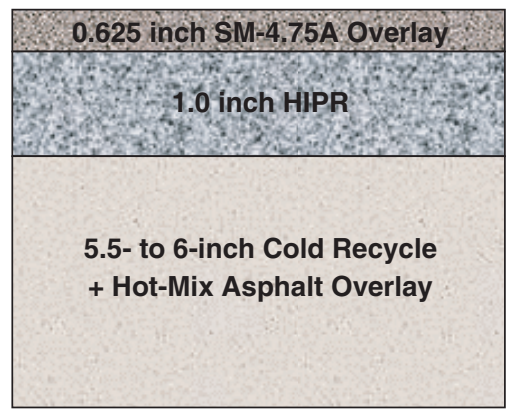

(b)

FIGURE 2 Pavement cross sections of (a) US-160 and (b) K-25 projects. 
TABLE 5 Mixture Compositions for Kansas SM-4.75A Mix on US-160 and K-25

\begin{tabular}{|c|c|c|c|}
\hline $\begin{array}{l}\text { Aggregate } \\
\text { Designation }\end{array}$ & $\begin{array}{l}\% \text { in } \\
\text { Design Mix }\end{array}$ & $\begin{array}{l}\text { Aggregate } \\
\text { Designation }\end{array}$ & $\begin{array}{l}\% \text { in } \\
\text { Design Mix }\end{array}$ \\
\hline US-160 & & $\mathrm{K}-25$ & \\
\hline $\mathrm{CS}-1 \mathrm{~B}^{a}$ & 32 & $\overline{\mathrm{CG}-2^{d}}$ & 30 \\
\hline $\mathrm{CS}-2^{b}$ & 12 & $\mathrm{CG}-5^{e}$ & 33 \\
\hline $\mathrm{CS}-2 \mathrm{~A}^{b}$ & 7 & SSG-1 $1^{f}$ & 35 \\
\hline $\mathrm{CS}-2 \mathrm{~B}^{b}$ & 14 & MFS $-5^{g}$ & 2 \\
\hline SSG- $4^{c}$ & 35 & & \\
\hline $\begin{array}{l}\text { Design asphalt } \\
\text { content }(\%)\end{array}$ & 7.0 & $\begin{array}{c}\text { Design asphalt } \\
\text { content }(\%)\end{array}$ & 6.1 \\
\hline
\end{tabular}

${ }^{a}$ Crushed limestone.

${ }^{b}$ Crushed limestone screening.

${ }^{c}$ Sand must not exceed $35 \%$.

${ }^{d}$ Crushed gravel.

${ }^{e}$ Crushed gravel screening.

${ }^{f}$ Sand must not exceed $35 \%$

${ }^{g}$ Microsilica.

and the Kansas DOT agreed that the adequate rate for proper rejuvenation and minimal bleeding had been reached. Independent measurements showed actual application rates to be $0.16 \mathrm{~L} / \mathrm{m}^{2}$ and $0.23 \mathrm{~L} / \mathrm{m}^{2}\left(0.036\right.$ and $\left.0.05 \mathrm{gal} / \mathrm{yd}^{2}\right)$ for US-160 and $\mathrm{K}-25$, respectively. Application temperature was $77^{\circ} \mathrm{C}$ to $79^{\circ} \mathrm{C}\left(170^{\circ} \mathrm{F}\right.$ to $\left.175^{\circ} \mathrm{F}\right)$.

\section{CONSTRUCTION}

The US-160 and K-25 projects were constructed in June 2007. Construction lasted only a couple of days. Both projects experienced some delays due to stormy weather.

\section{Mixture Production and Placement}

The mixture production was fairly uneventful on K-25. A Boeing 400 counterflow drum mixer was used. The microsilica used in the mixture design was not used in production. Thus, only crushed gravel and natural sand were used. Because the plant had been used in a previous project, the drum was fairly clean. A total of 8,649 tons (19,068 kips) of mixture were produced. Some placement problems (due to the very thin nature of the overlay) down the grade at one end of the project were corrected by being taken out and overlaid soon after construction.

The US-160 project used a Barber-Greene counterflow drum mix plant. A thunderstorm happened during production, and inadequate drying of sand was observed. This resulted in "mud balls" in the mixture placed; those at the surface were pulled out by the project inspector. The contractor produced 9,849 tons of mixture on this project.

\section{Compaction}

Because of the ultrathin nature of the overlay, no density was specified for this project. Compaction was done by steel-wheeled roller, and the rolling pattern (sequence) was established at the beginning of the project. In Kansas, rolling patterns are established by rolling, checking the density with the nuclear density meters, rolling more, checking density again, rolling more, and so on, until the density increase levels off (i.e., density is not increasing any more). The number of roller passes when density levels off then establishes the rolling pattern.

\section{QUALITY CONTROL AND QUALITY ASSURANCE}

Kansas quality control and quality assurance specifications using percentage within limits were also applied to these projects. These specifications called for dividing a mixture production lot of 3,000 tons into four sublots of 750 tons each. Samples were tested for asphalt content (AC), air voids (Va), VMA, voids filled with asphalt (VFA), initial density $\left(\% G_{\mathrm{mm}} @ N_{\text {ini }}\right)$, final density $\left(\% G_{\mathrm{mm}} @ N_{\max }\right)$, and dust-to-binder ratio.

\section{Quality Control for US-160}

Figure 3 shows the control charts for asphalt content, air voids, and VMA. The charts indicate that the mixtures were produced on the drier side, that is, asphalt content was always lower than design asphalt content. Air voids were somewhat higher for the first two sublots but were quickly adjusted and were close to the target value. Except for one sublot, VMA was always higher than the required minimum. Only one modified Lottman test was done for this project. Despite having an antistripping agent, tensile strength ratio was less than $80 \%$. This was a failing result according to current Kansas DOT specifications.

\section{Quality Assurance for K-25}

Figure 4 shows quality assurance results for asphalt content, air voids, VMA, VFA, initial density, final density, and dust-to-binder ratio. The mixtures on this project were produced on the wetter side, that is, asphalt content was always higher than design asphalt content. The dust-to-binder ratio was out of specification for two sublots.

\section{PERFORMANCE OF 4.75-mm NMAS PROJECTS}

\section{Preconstruction Conditions of US-160 and K-25}

The condition survey conducted in 2006 on US-160 before rehabilitation showed the average international roughness index (IRI) to be $1.22 \mathrm{~m} / \mathrm{km}$ (89 in./mi) on the right wheel path with a standard deviation of $0.19 \mathrm{~m} / \mathrm{km}$ (14 in./mi) (7). In Kansas, a South Dakota-type profilometer equipped with laser sensors is used to collect roughness data. Roughness in terms of the IRI in inches per mile is calculated from the left and right wheel path profiles. Rut depths are calculated from the profile elevation points collected by the sensors on both wheel paths and in the middle. There was no appreciable rutting, but two mile-long segments had 10 (33) and 27 (88) lineal meters (feet) of Code 1 fatigue cracking (hairline alligator cracking with non- 


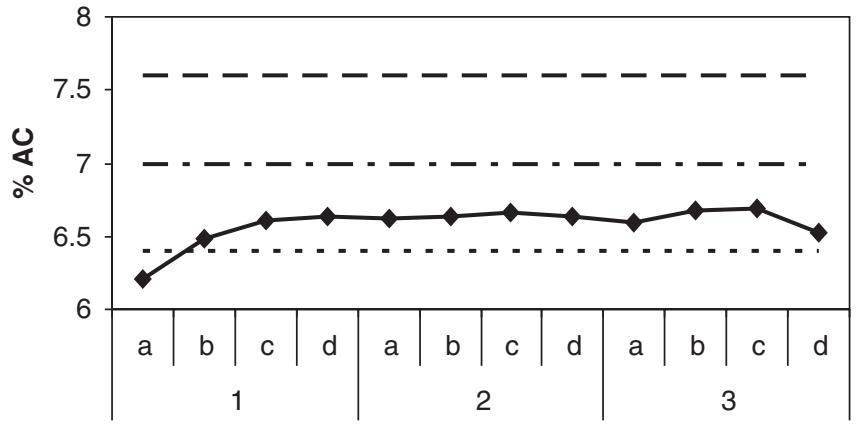

Field Lot and Sublot

$\longrightarrow$ Measured - - Max. \% AC - - - Min. \% AC - - - Target

(a)

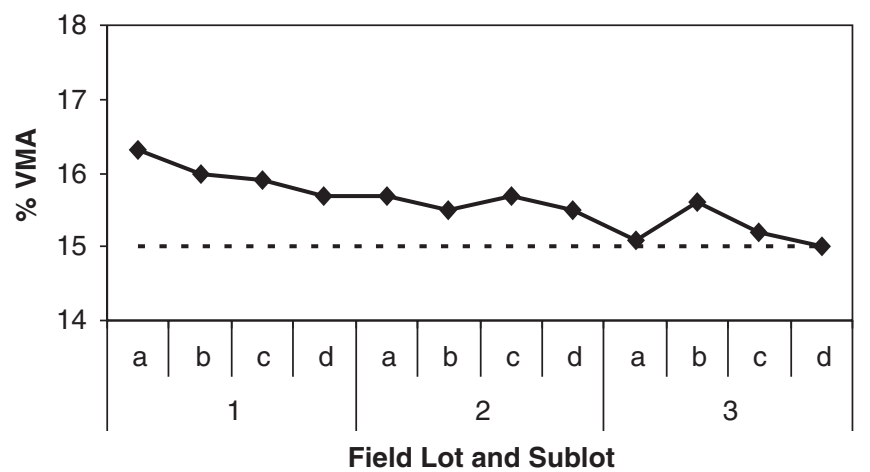

$\longrightarrow$ Measured $\cdots-\cdot$ Min. \% VMA

(c)

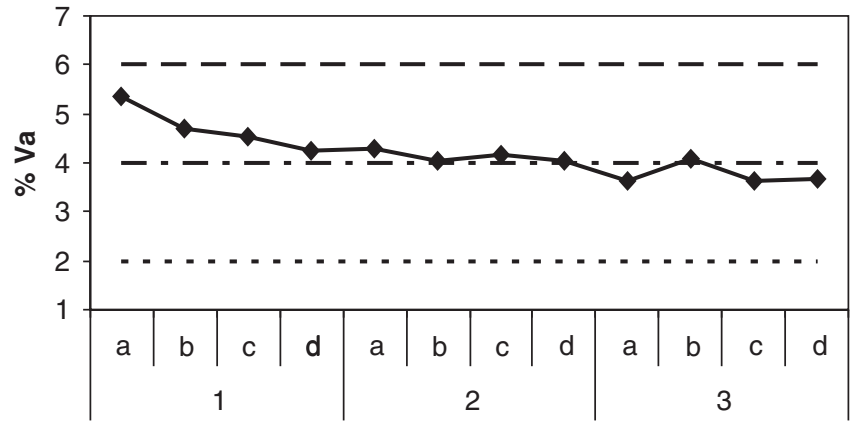

Field Lot and Sublot

$\longrightarrow$ Measured - - Max. \% Va - - - Min. \% Va - - - Target

(b)

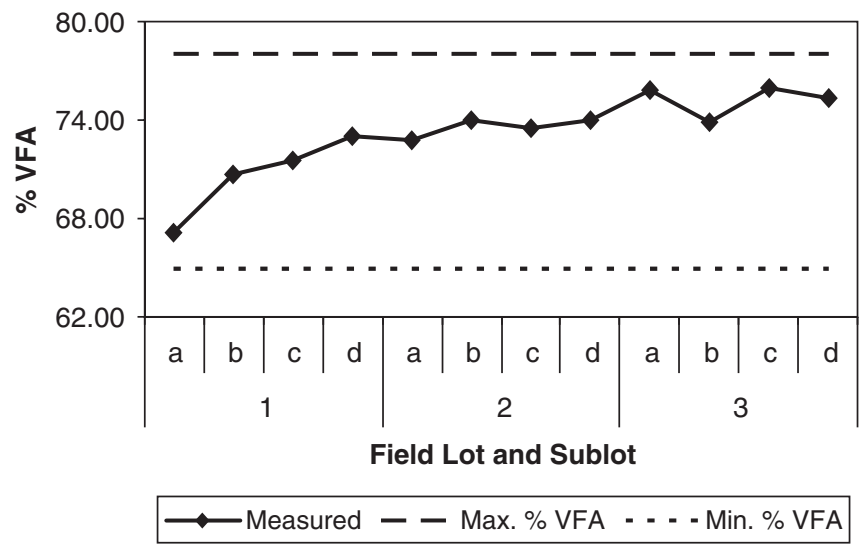

(d)

FIGURE 3 Field quality control of SM-4.75A mix on US-160 based on percentage of $(a) A C,(b) \mathrm{Va},(c)$ VMA, and $(d)$ VFA.

removable pieces) per $30.5 \mathrm{~m}$ (100 ft) of wheel path. The project had, on average, 11 Code 1 and 10 Code 2 transverse cracks, respectively. Code 1 transverse cracking in Kansas refers to full roadway-width cracks with no roughness, $6.35 \mathrm{~mm}(0.25 \mathrm{in}$.) or wider, with no secondary cracking; or any width with secondary cracking less than $1.2 \mathrm{~m} /$ lane ( $4 \mathrm{ft} /$ lane); or any width with a failed seal ( $\geq 1 \mathrm{ft} / \mathrm{lane})$. Code 2 cracks refer to any width with noticeable roughness due to depressions or bumps or wide cracks greater than 1 in.; cracks that have more than $4 \mathrm{ft}$ of secondary cracking per lane but no roughness; and sealed cracks with noticeable roughness. Table 6 summarizes the preconstruction conditions of the roadway on US-160 and $\mathrm{K}-25$ (7).

The condition survey conducted on K-25 in 2006 before rehabilitation showed the average IRI to be $1.3 \mathrm{~m} / \mathrm{km}$ (93 in. $/ \mathrm{mi})$ on the right wheel path with a standard deviation of $0.14 \mathrm{~m} / \mathrm{km}$ (10 in. $/ \mathrm{mi})$. There was no appreciable rutting. On average, the 16-mi-long pavement section had 27 (88) linear meters (feet) of Code 1 fatigue cracking (hairline alligator cracking with nonremovable pieces) per $30.5 \mathrm{~m}$ (100 ft) of wheel path. The project had, on average, 17 Code 0 transverse cracks. Code 0 transverse cracking in Kansas refers to full roadway-width sealed cracks with no roughness and sealant breaks less than $1 \mathrm{ft} /$ lane. Only one pavement management system segment had three Code 1 transverse cracks (7).

\section{Overlay Performance 3 Years After Construction}

\section{US-160, Harper County}

Figure 5 shows the performance history of the project 3 years after overlaying on US-160. The HIPR and overlay resulted in a remarkable improvement-24\% decrease - in roughness. Overall, US-160 was smoother than $\mathrm{K}-25$. The rutting $2.5 \mathrm{~mm}$ (0.1 in.) was fully addressed immediately after construction. However, an average 0.1-mm (0.004-in.) rut value was reported by the Kansas Pavement Management Information System (PMIS) in 2010. Equivalent transverse cracks (ETCR) (0.05 in.) were visible after 2 years of traffic operation, while at the end of the third year, the Kansas PMIS reported a significant increase (76\%) in transverse cracks. Scuffing and gouging of these small-sized mixtures were real concerns. US-160 seems to be doing fairly well and showed these issues were unfounded.

\section{K-25, Rawlins County}

Figure 6 shows the performance history of the K-25 route 3 years after rehabilitation. The HIPR and overlay decreased $23 \%$ of the roughness 


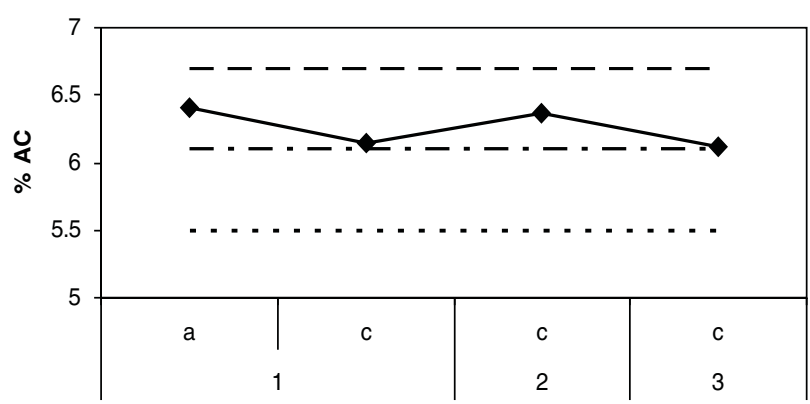

Lot and Sublot

$\longrightarrow$ Measured — - Max. \% AC . . . - Min. \% AC — - - Target

(a)

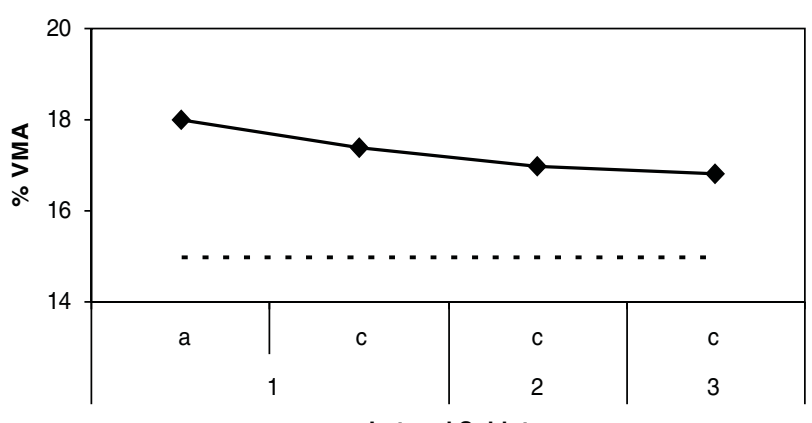

Lot and Sublot

$\rightarrow$ Measured . . - Min. \% VMA

(c)

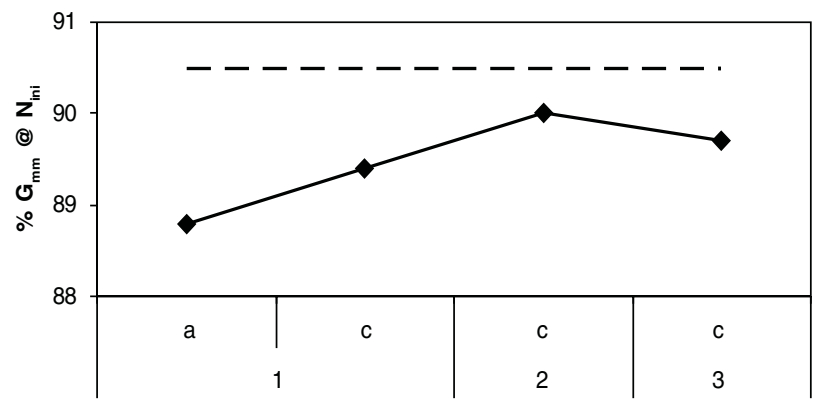

Lot and Sublot

$\longrightarrow$ Measured $\quad-$ Max. \% $\mathrm{G}_{\mathrm{mm}} @ \mathrm{~N}_{\mathrm{ini}}$

(e)

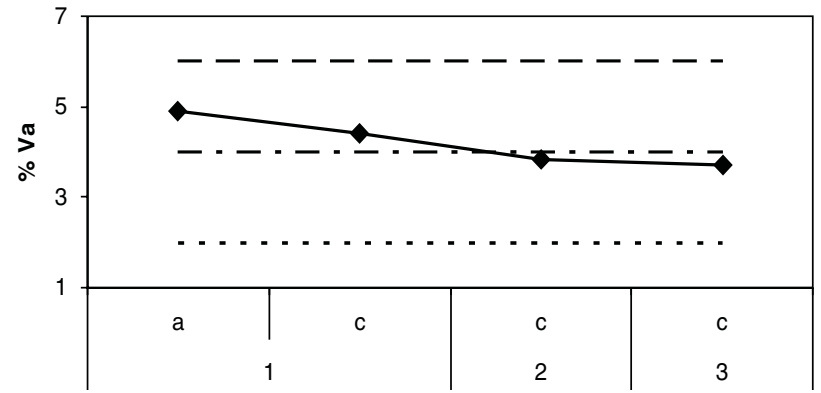

Lot and Sublot

$\neg$ Measured - - Max. \% Va - - - Min. \% Va — - - Target

(b)

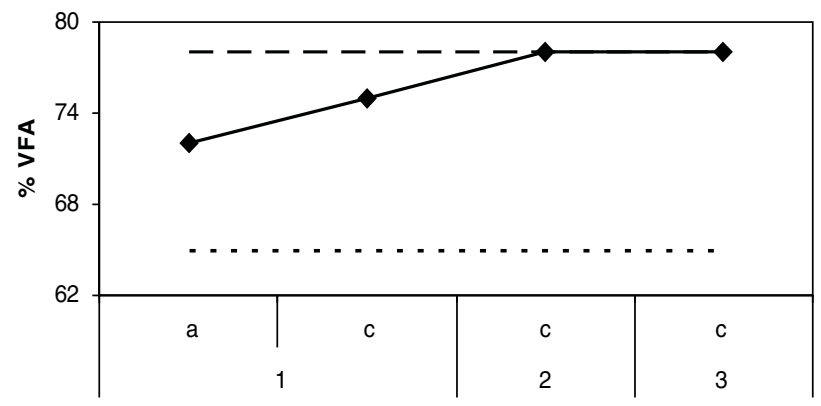

Lot and Sublot

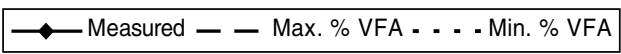

(d)

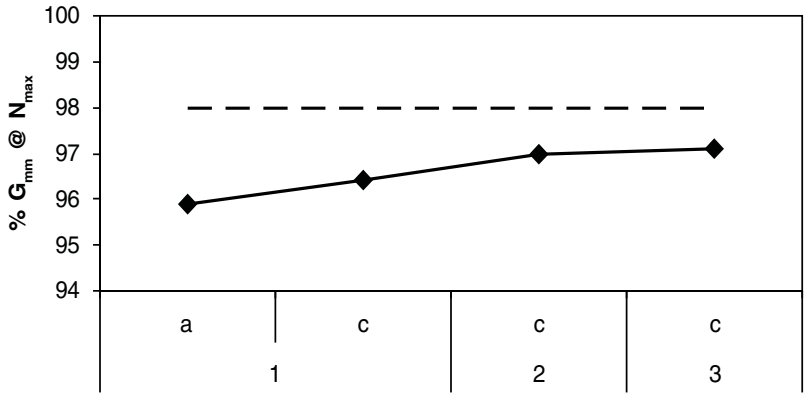

Lot and Sublot

$\neg$ Measured - Max. $\% \mathrm{G}_{\mathrm{mm}} @ \mathrm{~N}_{\max }$

(f)

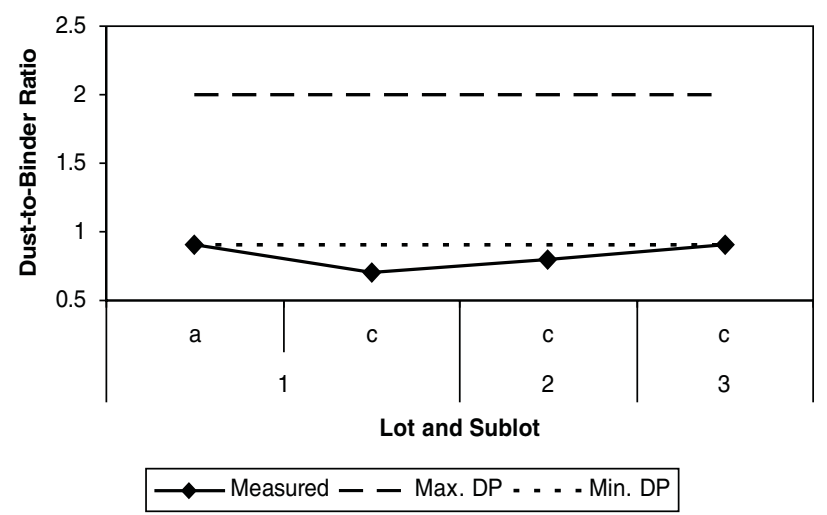

(g)

FIGURE 4 Quality assurance of SM-4.75A mix on K-25 project based on percentage of $(a) A C,(b) \mathrm{Va},(c)$ VMA, $(d)$ VFA, (e) $G_{\mathrm{mm}} @ N_{\mathrm{ini}}$, and $(f) G_{\mathrm{mm}} @ N_{\max }$, and ( $g$ ) dust-to-binder ratio. (DP = dust proportion.) 
TABLE 6 Roadway Performance Conditions on Route US-160 and K-25 Before 2007 Overlay Application (7)

\begin{tabular}{|c|c|c|}
\hline \multirow[b]{2}{*}{ Performance Measure } & \multirow{2}{*}{$\begin{array}{l}\text { US-160 (18 mi) } \\
\text { Conventional } \\
\text { Seal in } 2003\end{array}$} & \multirow{2}{*}{$\begin{array}{l}\mathrm{K}-25(16.018 \mathrm{mi}) \\
\text { 4-in. Recycle Cold } \\
\text { and 1.5-in. Overlay } \\
\text { in } 1999\end{array}$} \\
\hline & & \\
\hline IRI (in./mi) & 89 & 93 \\
\hline $\begin{array}{l}\text { Equivalent transverse } \\
\text { cracking (ETCR) }\end{array}$ & 0.5 & 0.32 \\
\hline Rutting (in.) & 0.097 & 0.156 \\
\hline $\begin{array}{l}\text { Equivalent fatigue cracking } \\
\text { (EFCR) }\end{array}$ & 1.42 & 9.99 \\
\hline
\end{tabular}

NoTE: 1 in. $/ \mathrm{mi}=0.014 \mathrm{~m} / \mathrm{km}$.

immediately after construction. Overall, roughness of the roadway was fairly consistent during the past 3 years under traffic. The 3.8-mm (0.15-in.) rutting was successfully addressed by overlay action, and a very minor rut value (0.005 in.) was reported by the Kansas PMIS in 2010. K-25 had transverse cracking that was also addressed by HIPR and the overlay. However, a cursory survey in 2009 indicated that transverse cracks are returning on this project. In 2010, the Kansas
PMIS reported a significant increase (81\%) in transverse cracks on the K-25 route. Again, scuffing and gouging were not found.

\section{CONCLUSIONS AND RECOMMENDATIONS}

Overall, Kansas's experience with 4.75-mm NMAS mixture has been varied. Both projects had construction issues. The US-160 project showed that extended aggregate drying and drum cleaning would be necessary when producing these mixtures. Performance history after overlay construction showed that roughness of the road surface was significantly improved and has remained consistent over the 3 years after construction. Transverse cracks seem to be the most challenging issue in maintaining the pavement surface in good condition. Rutting was not a major concern for the pavement surface for either project over the 3-year period. Crushed gravel aggregates seemed to perform better in the mixture than crushed limestone aggregates. A higher-grade binder (PG 70-22 instead of PG 64-22) may be needed to address the transverse cracking issues.

\section{ACKNOWLEDGMENT}

The authors acknowledge financial support provided by the Kansas Department of Transportation under its Kansas Transportation and New Developments (K-TRAN) program.

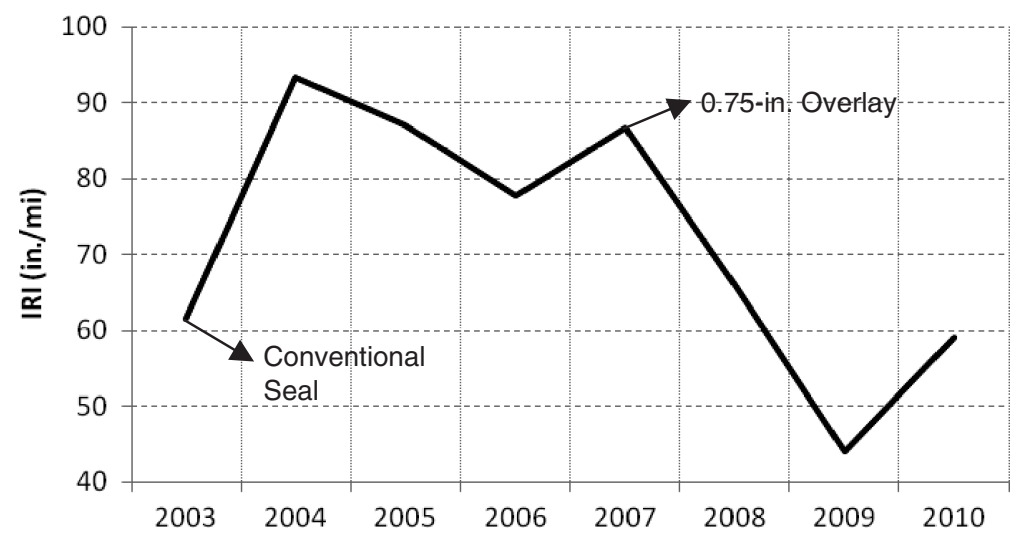

(a)

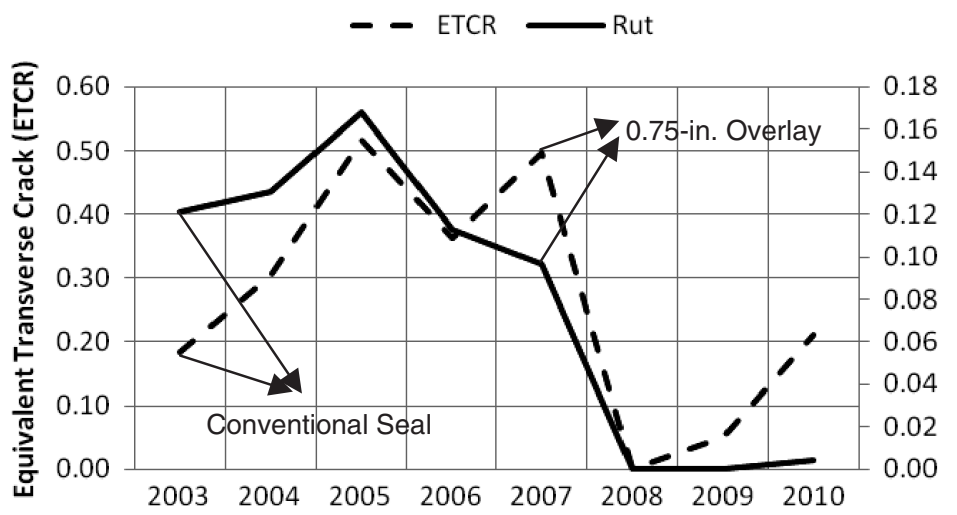

(b)

FIGURE 5 Performance history: $(a)$ IRI and $(b)$ distresses on US-160 before and after overlay application. 


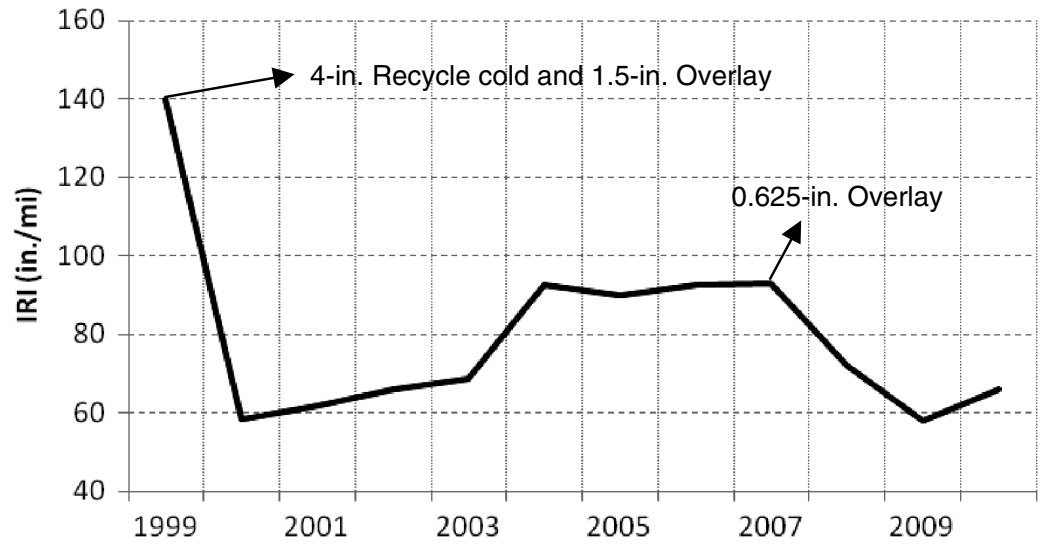

(a)

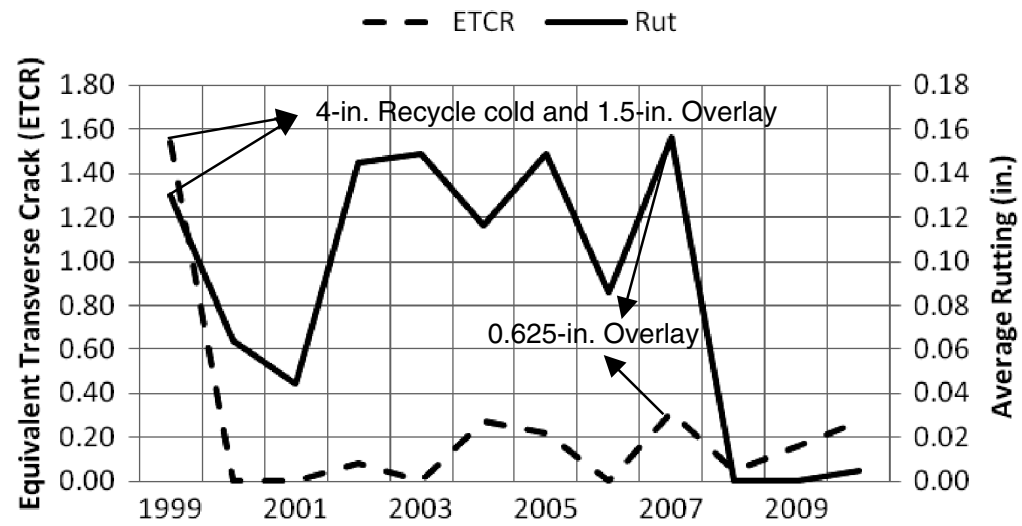

(b)

FIGURE 6 Performance history showing (a) IRI and $(b)$ distresses on K-25 before and after overlay application.

\section{REFERENCES}

1. Cooley, L. A., R. S. James, and M. S. Buchanan. Development of Mix Design Criteria for 4.75-mm Superpave Mixes. NCAT final report 02-04. National Center for Asphalt Technology, Auburn University, Auburn, Ala., 2002.

2. Williams, S. G. Development of 4.7-mm Superpave Mixes. MBTC report 2030. Department of Civil Engineering, University of Arkansas, Fayetteville, 2006.

3. West, R. C., D. M. Rausch, and O. Takahashi. Refinement of Mix Design Criteria for 4.75-mm Superpave Mixes. 10th International Conference on Asphalt Pavement, Vol. 1, 2006, pp. 161-170.

4. West, R. C., and D. M. Rausch. Laboratory Refinement of 4.75-mm Superpave Designed Asphalt Mixture. NCAT Phase I draft report. National Center for Asphalt Technology, Auburn University, Auburn, Ala., 2006.
5. Mallick, R. B., L. A. Cooley, R. L. Bradbury, and D. Peabody. An Evaluation of Factors Affecting Permeability of Superpave Designed Pavements. NCAT report 03-02. National Center for Asphalt Technology, Auburn University, Auburn, Ala., 2003.

6. Hossain, M., R. G. Maag, and G. Fager. Handbook of Superpave Volumetric Asphalt Mixture Design and Analysis. Superpave Certification Training Manual. Kansas State University, Manhattan, 2009.

7. Pavement Management System. 2007 NOS Condition Survey Report. Kansas Department of Transportation, Topeka. www.ksdot.org/matreslab/ pmis/2007/CSR2007_SW.pdf. Accessed Aug. 15, 2010.

The Committee for the 10th International Conference on Low-Volume Roads peer-reviewed this paper. 